\title{
Optimizing Fracture Prevention in Patients with Osteoporosis
}

\author{
Cheryl Lambing, MD, Anna Moll, MBA, and Michael Hite, MFA
}

Purpose: This Maintenance of Certification activity was designed to help address gaps in osteoporosis management, provide practice improvement based on recognized models, and evaluate the impact of the initiative.

Methods: The program comprised 3 stages: stage A, practice self-assessment and chart review; stage $B$, an intervention to address at least 1 problem; and stage $C$, additional chart review (new patients). Data from stages $A$ and $C$ were compared to evaluate the impact of the activity.

Results: Of 217 registrants, 62 completed the program, reviewing 2107 and 1814 charts in stages $A$ and $\mathrm{C}$, respectively. Statistically significant improvements occurred in all quality attributes from stage A to stage $C$ in 6 specified domains, except for the proportion of patients with an osteoporosis diagnosis.

Conclusions: Results of this activity support the benefit of performance improvement initiatives and are consistent with other reports. (J Am Board Fam Med 2015;28:819-821.)

Keywords: Certification, Osteoporosis, Quality Improvement, Quality of Health Care

Mandatory changes in board certification requirements, that is, Maintenance of Certification (MOC), have resulted in quality care and performance improvement initiatives and programs. Published data supporting behavioral changes resulting from such programs are limited. The MOC activity reported here was designed to address gaps in osteoporosis management, provide practice improvement based on recognized models for such activities (eg, the METRIC Diabetes Module offered by the American Academy of

This article was externally peer reviewed.

Submitted 26 February 2015; revised 29 April 2015; accepted 4 May 2015.

From the Ventura County Health Care Agency, Family Medicine Residency Program, Ventura County Medical Center, Ventura, CA (CL); the Annenberg Center for Health Sciences at Eisenhower Medical Center, Rancho Mirage, CA (AM, MH).

Funding: The costs related to the technology platform for the project were supported through an educational donation provided by Amgen (HCCOPS-25223). The Annenberg Center for Health Sciences at Eisenhower Medical Center provided management support and funded the costs of content development.

Conflict of interest: none declared.

Corresponding author: Cheryl Lambing, MD, Ventura County Health Care Agency, Medical Education Office, 3291 Loma Vista Rd, Bldg 340, Ventura, CA 93003 (E-mail: Cheryl.Lambing@ventura.org).
Family Physicians), ${ }^{1}$ and evaluate the impact of the activity in improving practice attributes and adherence to national standards of care. The results of this initiative are presented herein, adding to data demonstrating that this approach can be effective in changing practice.

\section{Methods}

This online activity was developed by the Annenberg Center for Health Sciences at Eisenhower Medical Center (Rancho Mirage, CA). The Annenberg Center has been approved by the American Board of Family Medicine for this activity as an external provider of MOC for Family Physicians Part IV credit. The Annenberg Center is also accredited by the Accreditation Council for Continuing Medical Education to provide continuing medical education for physicians. The activity comprised 3 stages. In stage A, physicians assessed practice attributes for 6 domains (such as organization, community linkages, and clinical information systems) and conducted chart reviews to establish their baseline on 4 quality measures derived from the Physicians Consortium for Performance Improvement library of measures and developed from national practice guidelines $^{2}$ (Table 1). Patients for chart 
Table 1. Comparison of Stage A and Stage C Results

\begin{tabular}{|c|c|c|c|c|}
\hline Parameter & Stage A Result & Stage C Result & $P$ Value & $\begin{array}{l}\text { Cluster-Adjusted } \\
P \text { Value }\end{array}$ \\
\hline Age, years $($ mean $\pm S D)$ & $72.7 \pm 10.2$ & $73.4 \pm 9.2$ & $.048^{*}$ & \\
\hline Female sex & $1919 / 2107(91.1 \%)$ & $1698 / 1814(93.6 \%)$ & $.003^{\dagger}$ & \\
\hline $\begin{array}{l}\text { Fracture of hip, spine, or distal } \\
\text { radius (yes) }\end{array}$ & $576 / 2107(27.3)$ & $482 / 1814(23.8)$ & $.01^{\dagger}$ & \\
\hline Diagnosed with osteoporosis & $1200 / 2107(57.0)$ & $1045 / 1814(57.6)$ & $.68^{+}$ & \\
\hline $\begin{array}{l}\text { Central DXA measurement since } \\
\text { age } 60\end{array}$ & $1267 / 1622(78.1)$ & $1278 / 1537(83.2)$ & $.0003^{\dagger}$ & .03 \\
\hline $\begin{array}{l}\text { Central DXA measurement } \\
\text { ordered or performed }\end{array}$ & $376 / 569(66.1)$ & $355 / 429(82.8)$ & $<10^{-5 \dagger}$ & .002 \\
\hline Prescribed pharmacologic therapy & $1111 / 2084(53.3)$ & $1062 / 1805(58.8)$ & $.0005^{\dagger}$ & .02 \\
\hline Prescribed calcium and vitamin D & $1082 / 1200(90.2)$ & $993 / 1045(95.0)$ & $.00001^{\dagger}$ & .02 \\
\hline $\begin{array}{l}\text { Counseling for calcium, vitamin D, } \\
\text { and exercise }\end{array}$ & $949 / 1200(79.1)$ & $940 / 1045(90.0)$ & $<10^{-5 \dagger}$ & $<.0001$ \\
\hline
\end{tabular}

Data are $\mathrm{n} / \mathrm{N}(\%)$ unless otherwise indicated.

*2-sample $t$ test.

${ }^{\dagger} \chi^{2}$ test.

DXA, dual X-ray absorptiometry; SD, standard deviation.

review had to be women aged $\geq 65$ years, men or women aged $\geq 50$ years who had had a fracture of the hip, spine, or distal radius; or men or women aged $\geq 50$ years who had an established diagnosis of osteoporosis. In stage B, participants selected an intervention (prespecified or their own action item) to address at least 1 problem area. After at least 1 month, participants conducted additional chart reviews for a different set of patients meeting the same criteria (stage C) to assess practice and performance changes from stage A. Data from stages A and $\mathrm{C}$ were compared.

\section{Results}

Of 217 physicians who registered between December 28, 2011, and October 31, 2013, 62 completed stages $\mathrm{A}, \mathrm{B}$, and $\mathrm{C}$ of the performance improvement module, reviewing 2107 and 1814 charts in stages $\mathrm{A}$ and $\mathrm{C}$, respectively. Positive shifts occurred in practice attributes from stage A to stage $C$ across all 6 domains. For example, when assessing the organization of the practice, $66 \%$ of the responses in stage A were that the approach to osteoporosis is not systematic. In stage $\mathrm{C}$, that percentage was $39 \%$, a decrease (improvement) of 27 percentage points. Significant improvements occurred in all quality attributes from stage A to stage C, except for the proportion of patients with an osteoporosis diagnosis (Table 1). When results were reanalyzed for each outcome using cluster adjustment to account for physician variation, all comparisons remained significantly different. All differences in outcome variables between stages A and $\mathrm{B}$ also remained significant in the multivariate model that adjusted for age, sex, and previous fracture. Participants who evaluated the program rated it highly across all stages. Program ratings on all questions ranged from 4.7 to 5.4, with 6 being the highest and 1 the lowest.

\section{Conclusions}

This practice improvement intervention to optimize fracture prevention resulted in significant improvements in all key performance measures other than the percentage of patients receiving a diagnosis of osteoporosis. Results were consistent with other practice improvement initiatives for osteoporosis and other areas of medicine. ${ }^{3-5}$ Improvements demonstrated in this activity support the benefit of performance improvement initiatives and provide a foundation for ongoing research including associations between performance improvement and health outcomes.

Philip A. Dombrowski, MBA, then president and CEO, The Annenberg Center for Health Sciences at Eisenhower Medical Center, Rancho Mirage, CA, was involved in program conceptualization, development, and implementation. Editorial assistance was provided by Paula G. Davis, PhD, Medical Communications, Inc., Tequesta, FL, and Kathleen Major, KMajor Editorial Services, Mahwah, NJ. Statistical analyses were con- 
ducted by Martin L. Lee, PhD, CStat, CSci, Adjunct Professor, Biostatistics, UCLA School of Public Health, Los Angeles, CA.

\section{References}

1. Peterson LE, Blackburn BE, Puffer JC, Phillips RL Jr. Family physicians' quality interventions and performance improvement through the ABFM diabetes performance in practice module. Ann Fam Med 2014;12: 17-20.

2. American Medical Association, National Committee for Quality Assurance. Osteoporosis Physician Performance Measurement Set. (CPT Copyright 2008). Chicago IL. American Medical Association; 2009;1-18.
3. Hess BJ, Johnston MM, Iobst WF, Lipner RS. Practice-based learning can improve osteoporosis care. J Am Geriatr Soc 2013;61:1651-60.

4. Hirsch FR, Jotte RM, Berry CA, Mencia WA, Stowell SA, Gardner AJ. Quality of care of patients with non-small-cell lung cancer: a report of a performance improvement initiative. Cancer Control 2014;21:90-7.

5. Peterson LE, Blackburn B, Phillips RL, Puffer JC. Improving quality of care for diabetes through a maintenance of certification activity: family physicians' use of the chronic care model. J Contin Educ Health Prof 2014;34:47-55. 